\title{
Role of Conserved Transmembrane Domain Cysteines in Activation of Metabotropic Glutamate Receptor Subtype 6
}

\author{
Kalyan C Tirupula1, Harpreet Kaur Dhiman', Leelavati Murthy ${ }^{1,3}$, Alessandro Bisello² and Judith Klein-Seetharaman ${ }^{1 *}$ \\ ${ }^{1}$ Department of Structural Biology, University of Pittsburgh School of Medicine, Pittsburgh, PA 15260, USA \\ ${ }^{2}$ Department Pharmacology and Chemical Biology, University of Pittsburgh School of Medicine, Pittsburgh, PA 15260, USA \\ ${ }^{3}$ Community College of Allegheny County, Monroeville, PA 15146, USA
}

\begin{abstract}
Metabotropic glutamate receptor subtype 6 (mGluR6) is a Class C type G protein coupled receptor (GPCR) uniquely expressed on retinal bipolar cells. mGluR6 plays a key role in dim-light vision but little is known about its structure and function. Here, we characterized the role of the three transmembrane (TM) cysteines in activation through site-directed mutagenesis. Function of the receptors in cells and membranes was assayed using cAMP and $\mathrm{G}$ protein activation, respectively. Cysteine mutants in TM helix V displayed slightly elevated or wild-type like activity. In contrast, all mutations involving the cysteine in TM helix VI lacked agonist response. Our results suggest that TM $\mathrm{VI}$ plays a key role in Class $\mathrm{C}$ activation similar to that observed in rhodopsin-like (Class A) GPCRs.
\end{abstract}

Keywords: G protein coupled receptor (GPCR); Metabotropic glutamate receptor (mGluR6); Transmembrane domain; cAMP assay; GTP - Europium (GTP-Eu) assay

Abbreviations: cAMP: Cyclic Adenosine Monophosphate; EC: Extracellular; Eu: Europium; FK: Forskolin; GPCRs: G Protein Coupled Receptor; GTP: Guanosine-5'-Triphosphate; IC: Intracellular; L-AP4: L-(+)-2-Amino-4-Phosphonobutyric Acid; LY341495: (2S)-2-Amino2-[(1S,2S)-2-Carboxycycloprop-1-yl]-3-(xanth-9-yl) Propanoic Acid; mGluRs: Metabotropic Glutamate Receptors; mGluR6: Metabotropic Glutamate Receptor Type 6; TM - Transmembrane

\section{Introduction}

Metabotropic glutamate receptors (mGluRs) are G protein coupled receptors (GPCRs) that modulate glutamate-mediated neuronal signaling and are implicated in different brain functions and dysfunctions [1]. The GPCR family is divided into at least five distinct sub-families and mGluRs belong to the class Csub-family. Different subtypes of mGluRs are further divided into group I (mGluR1 and 5), group II (mGluR2 and 3) and group III (mGluR4, 6,7 and 8) based on sequence homology, signal transduction and pharmacological properties [2]. In contrast to other mGluRs, mGluR6 is uniquely expressed in retinal ON bipolar cells and is involved in dim-light vision [3]. Mutations in mGluR6 are the cause for autosomal recessive congenital stationary night blindness type 1 (CSNB1) [4-6]. mGluR6 has also been implicated in heroin addiction and methadone maintenance treatment of chronic addiction through genome-wide association and pharmacogenetic studies $[7,8]$.

Despite its biological importance, mGluR6 is the least studied of all mGluRs. There are no structure-function studies of mGluR6 and its mechanism of activation is essentially unknown. Current knowledge of GPCR activation is derived primarily from studies on rhodopsin, and to a lesser extent from other class A GPCRs such as $\beta$-adrenergic, dopamine and chemokine receptors. All GPCRs consist of a transmembrane (TM) region comprising of seven helices, the G-protein interacting intracellular (IC) domain and an extracellular (EC) domain. While, in most Class A GPCRs ligands bind in the TM domain, class C GPCRs have uniquely evolved a large extracellular amino-terminal domain (ATD) that harbors the endogenous ligand binding pocket.

Conformational changes in the TM domain are known to be at the heart of the activation mechanism of Class A GPCRs [9-12]. Support that TM conformational changes are also important for mGluRs, in line with a general similarity between the activation mechanism employed by rhodopsin and mGluRs, has come from discovery of allosteric ligands. Allosteric ligands do not compete with glutamate for its binding pocket in the ATD, but instead bind to the TM domain, in a pocket similar to that of the retinal ligand in rhodopsin [13]. These ligands can positively or negatively modulate the response of mGluRs to glutamate and serve as agonists and antagonists in the absence of the ATD [14]. We have shown that the conformational changes observed in rhodopsin when translated to mGluRs can adequately explain whether a ligand is a positive or negative modulator in a large number of cases [15]. Thus, the TM domain may play a similar role in activation of all GPCRs as proposed in numerous studies [14,16-18], which we will refer to here as the "generality hypothesis". In this study, we characterized the role of conserved cysteines in the TM domain of human mGluR6 for activation and find experimental support for the generality hypothesis, highlighting in particular the importance of TM helix VI for activation.

\section{Materials and Methods}

\section{Homology modeling of TM region of human mGluR6}

A three-dimensional model of the TM region of human mGluR6 was created by homology modeling using MODELLER 9v8 [19]. Structures of bovine rhodopsin (PDB ID: 1U19), turkey $\beta_{1}$-adrenergic receptor (PDB ID: 2VT4), human $\beta_{2}$-adrenergic receptor (PDB ID: 2RH1) and human $A_{2 A}$ adenosine receptor (PDB ID: 3EML) that were available at the time of this study were used as templates to generate an average model for human mGluR6. The best model was picked based on MODELLER scores and by comparing Ramachandran plots created

*Corresponding author: Judith Klein-Seetharaman, Assistant Professor, Department of Structural Biology, University of Pittsburgh School of Medicine, Room 2051, Biomedical Science Tower 3,3501 Fifth Avenue, Pittsburgh, PA 15261, USA, Tel: 412383 7325; Fax: 412648 8998; E-mail: jks33@pitt.edu

Received June 28, 2012; Accepted September 13, 2012; Published September 15,2012

Citation: Tirupula KC, Dhiman HK, Murthy L, Bisello A, Klein-Seetharaman $\mathrm{J}$ (2012) Role of Conserved Transmembrane Domain Cysteines in Activation of Metabotropic Glutamate Receptor Subtype 6. Med chem 2: 119-125. doi:10.4172/2161-0444.1000126

Copyright: (c) 2012 Tirupula KC, et al. This is an open-access article distributed under the terms of the Creative Commons Attribution License, which permits unrestricted use, distribution, and reproduction in any medium, provided the original author and source are credited. 
by PROCHECK software [20]. For discussion of individual residues, the generic numbering proposed by Ballesteros and Weinstein [21] is included as a superscript.

\section{Buffers and Media for cell culture}

HEK293 cells were grown in DMEM or DMEM/F12 supplemented with fetal bovine serum or bovine serum (10\%), penicillin-streptomycin (100 units $/ \mathrm{ml})$ and if needed with blasticidin $(5 \mu \mathrm{g} / \mathrm{ml})$ or geneticin $(1-3 \mathrm{mg} / \mathrm{ml})$ [22]. Cells were maintained in a humidified incubator kept at $37^{\circ} \mathrm{C}$ and $5 \% \mathrm{CO}_{2}$.Cells were induced with media containing tetracycline $(2 \mu \mathrm{g} / \mathrm{ml})$ and sodium butyrate $(5 \mathrm{mM})$, while in the case of uninduced controls, tetracycline was omitted. Cells were washed with either phosphate buffered saline (PBS: $137 \mathrm{mM} \mathrm{NaCl}, 2.7 \mathrm{mM} \mathrm{KCl}$, $1.8 \mathrm{mM} \mathrm{KH} \mathrm{PO}_{4}, 10 \mathrm{mM} \mathrm{Na} \mathrm{HPO}_{4} \mathrm{pH} 7.2$ ) or Hanks' balanced salt solution (HBSS: $0.44 \mathrm{mM} \mathrm{KH}_{2} \mathrm{PO}_{4}, 0.34 \mathrm{mM} \mathrm{Na}_{2} \mathrm{HPO}_{4}, 137 \mathrm{mM} \mathrm{NaCl}$, $5.36 \mathrm{mM} \mathrm{KCl}, 1.26 \mathrm{mM} \mathrm{CaCl}_{2}, 0.81 \mathrm{mM} \mathrm{MgSO}_{4}, 4.17 \mathrm{mM} \mathrm{NaHCO}_{3}$, $5.55 \mathrm{mM} \mathrm{D}$-Glucose $\mathrm{pH} 7.3$ ). HBSS was also used to nutrient starve cells in preparation for functional assays and membrane preparations.

\section{Cloning and establishment of stable cell lines of wild-type} and cysteine mutants of human mGluR6

Human mGluR6 with a 1D4 tag at the C-terminus was sub-cloned from pMT4 [23] into a tetracycline inducible expression system vector pACMV-tetO [22]. The cysteine mutants were created using sitedirected mutagenesis (Agilent Technologies, Santa Clara, CA). A total of seven cysteine to alanine mutants comprising all possible mutations involving C754, C765 and C793 were created and categorized into double (C754A, C765A, C793A), single (C754A/C765A, C765A/ C793A, C754A/C793A) and cys-less (C754A/C765A/C793A) mutants. The nomenclature double, single and cys-less refers to the presence of two, one or no native cysteines in the TM helices of these mutants, respectively. This nomenclature was followed to reflect the number of cysteines which are predicted to exist in reduced form and hence, can be chemically derivitized in vitro for enabling future biophysical studies of mGluR6.

Tetracycline inducible HEK293S stable cell lines, selected maximal receptor expression, for WT and cysteine mutants were established as described previously [22].

\section{Immunofluorescence}

Immunostaining of cells was carried out $48-55 \mathrm{~h}$ post induction. Cells were fixed with $2 \%$ paraformaldehyde and were permeabilized with $0.1 \%$ Triton Xin PBS. To detect mGluR6, anti-1D4 (University of British Columbia, Vancouver, Canada) and Alexa Fluor ${ }^{\circledR} 488$ conjugated goat anti-mouse (Invitrogen, Carlsbad, CA) antibodies were used. Rhodamine-Phalloidin (Invitrogen, Carlsbad, CA) and DRAQ-5 (Biostatus, Leicestershire, United Kingdom) were used to detect cytoskeletal network (actin) and nucleus, respectively. Images were taken on a Leica TCS SL confocal fluorescence microscope (Center for Biological Imaging, University of Pittsburgh, PA).

\section{cAMP functional assay}

cAMP assays were performed as described [24], with the following optimization. Cells were grown in 24 -well plates coated with collagen. The wells were seeded with 0.1 million cells and were grown for 72 h. HBSS was used for all subsequent washes and to prepare ligand solutions. After $72 \mathrm{~h}$, cells were washed once and induced for $48 \mathrm{~h}$. The cells were then washed twice and loaded with $2 \mu \mathrm{Ci} / \mathrm{ml}$ of $\left[{ }^{3} \mathrm{H}\right]$ Adenine (PerkinElmer, Waltham, MA) for $2 \mathrm{~h}$. This was followed by one wash and treatment with $1 \mathrm{mM}$ of 3-isobutyl-1-methylxanthine (SigmaAldrich, St. Louis, MO). After this, LY341495 (Tocris Bioscience, Ellisville, MO) or HBSS was added directly to the cells from 10x stocks and incubated for another $15 \mathrm{~min}$. At this point, $10 \mu \mathrm{M}$ forskolin (Tocris Bioscience, Ellisville, MO) was added with or without L-glutamate or L-AP4 (Tocris Bioscience, Ellisville, MO), from 10x stocks. The plates were incubated for another $15 \mathrm{~min}$ and the reaction was stopped by addition of trichloroacetic acid. cAMP was isolated and measured by two-column chromatography [25].

The counts per minute values for different data points were expressed as the relative percentages of corresponding forskolinstimulated cAMP levels that were normalized to $100 \%$. Data analysis was performed using Sigma Plot 10.0 scientific graphing software using sigmoidal dose response curve fitting for determining $\mathrm{EC}_{50}$ values.

\section{GTP-Eu binding assay}

Membranes for GTP-Eu binding were prepared using a scaled up protocol originally communicated by Dr. Takahiro Yamashita (Department of Biophysics, Graduate School of Science, Kyoto University) [26]. GTP-Europium (PerkinElmer, Waltham, MA) binding assay reactions were performed in 96 wellAcroWell $^{\mathrm{ma}}$ plates (Pall Life Sciences, Ann Arbor, MI). The final reaction mixtures of 100 $\mu \mathrm{l} /$ well each contained $6 \mu \mathrm{g}$ membrane in $50 \mathrm{mM}$ HEPES ( $\mathrm{pH} 7.4$ ), $20 \mathrm{mM} \mathrm{NaCl}, 3 \mathrm{mM} \mathrm{MgCl}, 3 \mu \mathrm{M}$ GDP and $100 \mu \mathrm{g} / \mathrm{ml}$ saponin along with the desired concentration of ligands. For measuring non-specific binding, $5 \mu \mathrm{M}$ of GTP $\gamma \mathrm{S}$ was added to the reaction buffer. The plates with the reaction mixture were incubated at room temperature for 30 min. GTP-Eu reagent was then added to obtain a final concentration of $5 \mathrm{nM}$ and incubated for another $30 \mathrm{~min}$. The reaction was terminated and the wells were washed two times with $300 \mu \mathrm{l}$ of wash buffer (50 $\mathrm{mM}$ Tris- $\mathrm{HCl}$ ( $\mathrm{pH} 7.5), 10 \mathrm{mM} \mathrm{MgCl}_{2}$ ) using vacuum filtration. The fluorescence in the wells was measured immediately $(340 \mathrm{~nm}$ excitation $/ 615 \mathrm{~nm}$ emission, $0.4 \mathrm{~ms}$ delay and $0.4 \mathrm{~ms}$ window) using a VICTOR3 ${ }^{\text {ma }}$ Multilabel Plate Reader (PerkinElmer Life Sciences, Waltham, MA).

The non-specific binding (in presence of $5 \mu \mathrm{M}$ GTP $\gamma \mathrm{S}$ ) was subtracted from the total fluorescence counts to obtain specific binding. Specific binding was expressed as percent over basal binding (= [Specific binding of agonist - basal counts ${ }^{\star} 100 /$ [basal counts] $)$ where basal counts was defined as the specific binding observed in the absence of any ligand.

\section{Results}

Transmembrane cysteines in TM helices $\mathrm{V}$ and VI of human mGluR6 are conserved and are clustered in a three dimensional structure model

There are a total of 22 cysteines in human mGluR6 out of which five are in the TM region. A sequence alignment of TM only regions of 92 mGluRs from different organisms highlights the conservation profile of the five cysteines (Figure 1). Two of the five cysteines, C650 and C744, are conserved in all mGluRs (Figure 1 and Figure 2A) and are presumed to form a disulfide bond that is conserved throughout much of the GPCR family [17,27]. Of the three remaining cysteines in TM helices, C765 and C793 are conserved in all mGluRs, while C754 is conserved only in mGluR6. Interestingly, other members of group III mGluRs have a conserved cysteine immediately upstream of C754.

C754 and C793 are located in the middle of the TM helices as predicted in the three dimensional homology model of mGluR6 (Figure $2 \mathrm{~B}$ ). The $\mathrm{C} \beta-\mathrm{C} \beta$ distances calculated from the homology model for C754, C765 and C793range from $14 \AA$ to $18 \AA$, suggesting that they form a cluster on TM helix V and VI (Figure 2B). In other GPCRs, this region of TM helix V and VI is shown to play an important role for ligand binding and receptor activation (see Discussion). Based on their 


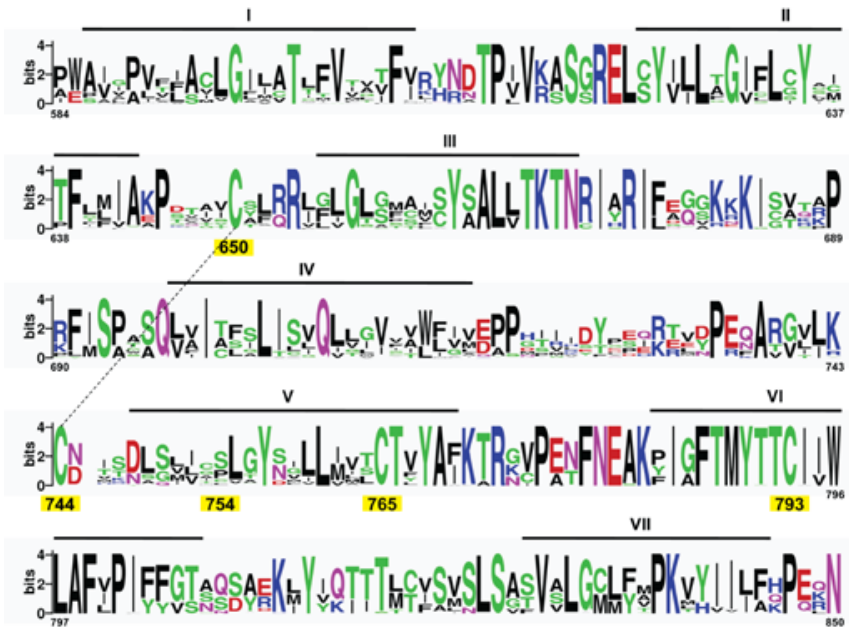

Figure 1: Multiple sequence alignment of the TM regions of mGluRs. ClustalW was used for the alignment and the figure was generated using Weblogo (http:// weblogo.berkeley.edu). The positions of conserved cysteines are highlighted in yellow. The individual letter height of aminoacid(s) at each position indicates their relative frequencies and conservation in the alignment. The TM helices are indicated as lines above the sequence.
A.

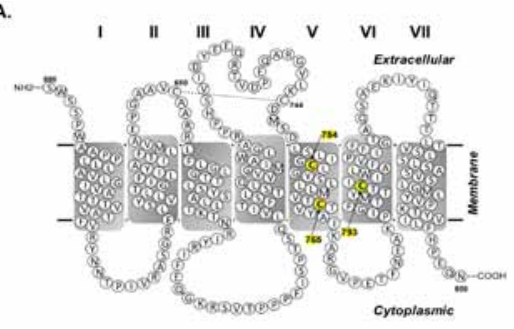

B.

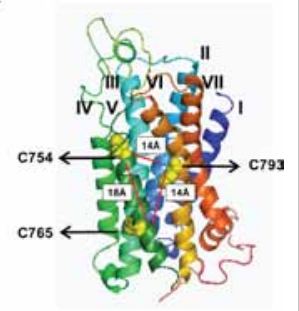

c.

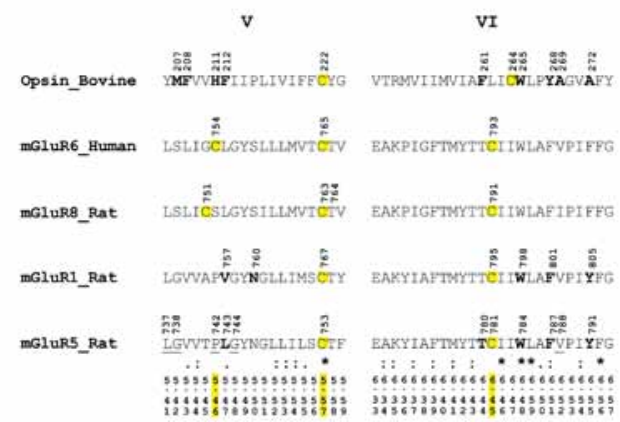

Figure 2: The location of cysteines $754^{5.46}, 765^{5.57}$ and $793^{6.45}$ is highlighted in (A) secondary structure model created using the TM boundary annotations from NCBI (NP 000834.2) and (B) three dimensional structure model along with overlay of the distances between $C \beta-C \beta$ atoms. (C) Sequence alignment of TM helices $\mathrm{V}$ and $\mathrm{VI}$ of rhodopsin (bovine), mGluR6 (human), mGluR8 (rat), mGluR1 (rat) and mGluR5 (rat). Residues within $5 \AA$ of the retinal ligand in rhodopsin (PDB: 1U19) and those critical for allosteric ligand binding in mGluR1 and 5 (34-36) are highlighted in bold.Residues that are predicted to be within $5 \AA$ of allosteric ligand binding pocket in mGluR5 are underlined (15) The Ballesteros Weinstein numbering scheme of the amino acids is provided at the bottom of alignment.

strong conservation, location and possible clustering in structure, the TM cysteines probably play a key role in mGluR6 activation.

Wild-type and cysteine mutants in stable cell lines are expressed on the membrane at comparable levels

Immunofluorescence studies show that mGluR6 is expressed only in induced cells and is localized both on the plasma membrane and inside the cells (Figure 3A and 3B). The intracellular localization of the receptor is expected as the stable cell lines for mGluR6 were selected for high levels of receptor expression.

Membrane preparations of WT and mutant mGluR6 were analyzed on a dot blot (Figure 3C) with rhodopsin as a positive control. Both WT and the cysteine mutants show strong expression in the membranes, while no expression was detectable in uninduced cells. The WT and mutant mGluR6 levels were quantified based on a densitometry derived standard curve of rhodopsin (Figure 3D). The receptor expression levels varied between $27 \mathrm{pM}$ to $148 \mathrm{pM}$ per mg of total membrane protein, suggesting comparable levels of mGluR6 expression across wild-type and mutants.

\section{L-glutamate and L-AP4 inhibit forskolin-stimulated cAMP formation in wild-type mGluR6 stable cell lines}

cAMP levels in cells are decreased on mGluR6 activation with agonists such as L-glutamateand L-AP4(28). L-AP4 produced a concentration dependent inhibition of forskolin-stimulated cAMP accumulation (Table 1) with an $\mathrm{EC}_{50}$ of $0.18 \pm 0.04 \mu \mathrm{M}$ (Figure $4 \mathrm{~A}$; Supplementary Table 2). The cAMP levels in presence of L-AP4 are $54 \pm 3 \%$ and $77 \pm 7 \%$ of forskolin-stimulated levels for induced and uninduced cells, respectively. The $\mathrm{EC}_{50}$ values and cAMP levels in the presence ofL-glutamate are $4 \pm 1 \mu \mathrm{M}$ and $50 \pm 2 \%$, respectively (Figure $4 \mathrm{~A}$; Supplementary Table 1 and 2). The $\mathrm{EC}_{50}$ values in our assays are similar to those reported previously and demonstrate that L-AP4 is a more potent agonist of mGluR6 compared to L-glutamate [28].

LY341495 exerts antagonist response and right-shifts the L-AP4 dose response curves of wild-type mGluR6 in cAMP assay

LY341495 is a potent antagonist for group II mGluRs and is

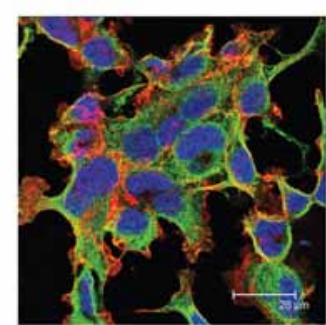

c.

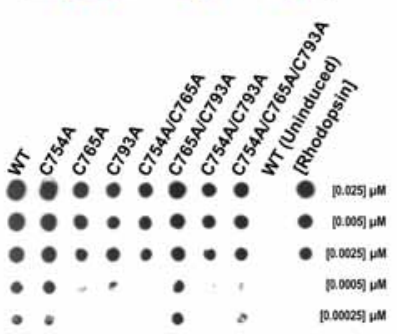

B.

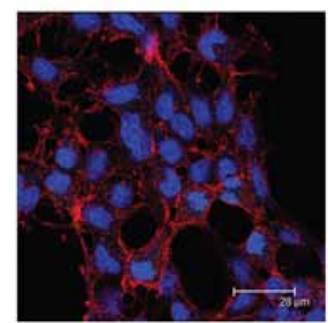

D.

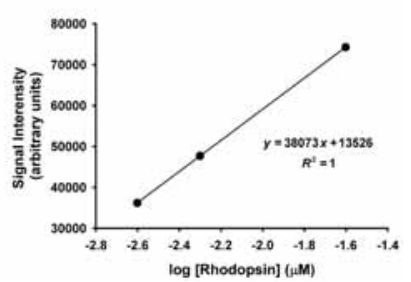

Figure 3: Wild-typemGluR6expression in (A) induced and (B) uninduced HEK293S stable cell lines.mGluR6, actin and nucleus are stained green, red and blue, respectively. (C) Dot blot with serial dilutions of membranes fromWT and cysteine mutants. Predetermined concentrations of rhodopsin are included on the dot blot as a positive control. Anti-1D4 antibody is used to probe both mGluR6 and rhodopsin. (D) Densitometry analysis of dot blot - signal (arbitrary units) versus concentration curve for rhodopsin used for estimating concentrations of WT and mutant mGluR6. The concentrations in $\mathrm{pM} / \mathrm{mg}$ of total membrane protein as derived from the standard curve are: WT: 88, C754A: 93, C765A: 38, C793A: 0.37, C754A/C765A: 27, C765A/C793A: 91, C754A/C793A: 40 and C754A/C765A/C793A: 128 


\begin{tabular}{|c|c|c|c|c|c|c|}
\hline \multirow{3}{*}{ Receptor construct } & \multicolumn{6}{|c|}{ cAMP formation ( $\%$ of forskolin stimulated cAMP levels) } \\
\hline & \multicolumn{2}{|c|}{ 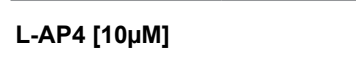 } & \multicolumn{2}{|c|}{ 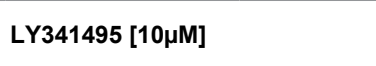 } & \multicolumn{2}{|c|}{$\begin{array}{l}\text { LY341495 }[10 \mu \mathrm{M}] / \\
\text { L-AP4 }[100 \mu \mathrm{M}]\end{array}$} \\
\hline & Induced & Uninduced & Induced & Uninduced & Induced & Uninduced \\
\hline Wild type & $54 \pm 3(7)$ & $77 \pm 7(2)$ & $246 \pm 6(4)$ & $106 \pm 8(3)$ & $47 \pm 1(3)$ & $90 \pm 1(3)$ \\
\hline \multicolumn{7}{|c|}{ Double cysteine mutants } \\
\hline C754A & $38 \pm 1(5)$ & $91 \pm 4(3)$ & $324 \pm 13(3)$ & $101 \pm 3(3)$ & $34 \pm 1(3)$ & $79 \pm 1(3)$ \\
\hline C765A & $37 \pm 2(5)$ & $95 \pm 3(3)$ & $205 \pm 4(3)$ & $99 \pm 2(3)$ & $36 \pm 2(3)$ & $88 \pm 4(3)$ \\
\hline C793A & $107 \pm 6(5)$ & $103 \pm 3(3)$ & $185 \pm 7(3)$ & $104 \pm 3(3)$ & $79 \pm 1(3)$ & $88 \pm 3(3)$ \\
\hline \multicolumn{7}{|c|}{ Single cysteine mutants } \\
\hline C754A/C765A & $52 \pm 5(6)$ & $83 \pm 3(8)$ & $199 \pm 23(6)$ & $102 \pm 2(6)$ & $50 \pm 3(6)$ & $91 \pm 3(6)$ \\
\hline C765A/C793A & $108 \pm 6(2)$ & $83 \pm 3(3)$ & $236 \pm 3(3)$ & $112 \pm 7(3)$ & $88 \pm 3(3)$ & $91 \pm 1(3)$ \\
\hline C754A/C793A & $80 \pm 3(4)$ & $98 \pm 3(3)$ & $201 \pm 8(3)$ & $104 \pm 4(3)$ & $82 \pm 3(3)$ & $101 \pm 6(3)$ \\
\hline \multicolumn{7}{|l|}{ Cys-less mutant } \\
\hline C754A/C765A/C793A & $79 \pm 3(5)$ & $87 \pm 5(4)$ & $275 \pm 12(3)$ & $91 \pm 4(3)$ & $70 \pm 1(3)$ & $84 \pm 5(3)$ \\
\hline
\end{tabular}

Table 1: cAMP levels in stable cell lines of wild-type and cysteine mutants of mGluR6 in presence of L-AP4 and LY341495. Data is represented as mean \pm SEM (number of independent experiments).

\begin{tabular}{|c|c|c|}
\hline Receptor construct & $\begin{array}{l}\text { Maximal binding } \\
\text { ( } \% \text { over basal at } 100 \mu \mathrm{M} \text { L-Glu) }\end{array}$ & $\begin{array}{l}E_{\max } \\
{[\% \text { of wildtype }]}\end{array}$ \\
\hline Wild type & $198 \pm 21(6)$ & 100 \\
\hline \multicolumn{3}{|c|}{ Double cysteine mutants } \\
\hline $\mathrm{C} 754 \mathrm{~A}$ & $229 \pm 15(3)$ & 116 \\
\hline C765A & $258 \pm 10(3)$ & 130 \\
\hline C793A & $122 \pm 6(4)$ & 62 \\
\hline \multicolumn{3}{|c|}{ Single cysteine mutants } \\
\hline $\mathrm{C} 754 \mathrm{~A} / \mathrm{C} 765 \mathrm{~A}$ & $134 \pm 11(5)$ & 68 \\
\hline C765A/C793A & $6 \pm 2(3)$ & 3 \\
\hline $\mathrm{C} 754 \mathrm{~A} / \mathrm{C} 793 \mathrm{~A}$ & $99 \pm 26(2)$ & 50 \\
\hline \multicolumn{3}{|l|}{ Cys-less mutant } \\
\hline C754A/C765A/C793A & $94 \pm 31(2)$ & 47 \\
\hline
\end{tabular}

Table 2: Comparison of GTP-Eu binding in the membranes from wild-type and cysteine mutants. Data is represented as mean \pm SEM (number of independent experiments). $\mathrm{E}_{\max }$ is the relative activity of mutants as compared to wild-type.

reported to exert antagonist response at group III mGluRs [29]. L-AP4 binding in cell membranes expressing human mGluR6 is reported to be selectively displaced by LY341495 with a $K_{\mathrm{d}}$ and $B_{\max }$ values of $31.6 \pm 6.8 \mathrm{nM}$ and $3.3 \pm 0.7 \mathrm{pmol} / \mathrm{mg}$ protein [30]. In our WT cell line, LY341495 produced a concentration dependent right-shift of the L-AP4 dose response curves with no effect on uninduced cells (Supplementary Figure 1A).The effect of LY341495 was completely reversed on addition of L-AP4 (Table 1). Schild analysis of L-AP4 dose response curves in presence of LY341495 was linear with a slope of $1.06 \pm 0.03$ (Supplementary Figure 1B), suggesting a simple competitive antagonism [31]. The $\mathrm{pK}_{\mathrm{B}}$ estimate, from Schild analysis, on constraining the slope to unity is 6.68 ( 6.5 to 6.8 at $95 \%$ confidence limits) corresponding to a potency of $0.2 \mu \mathrm{M}$ for LY341495.

Interestingly, apart from the competitive antagonism, enhanced cAMP formation in the presence of LY341495 was also observed (Table 1 and Supplementary Figure 1A). At $10 \mu \mathrm{M}$ concentration of LY341495, the cAMP levels were $246 \pm 6 \%$ and $106 \pm 8 \%$ of for skolinstimulated levels for induced and uninduced cells, respectively (Table 1). Our findings hint at a possible inverse agonism of LY341495 at group III mGluRs.

Transmembrane cysteine mutants respond unequally to agonist (L-AP4 and L-glutamate) but uniformly to LY341495 treatment in cAMP assays

The cAMP levels in double cysteine mutants C754A and C765Awere $38 \pm 1 \%$ and $37 \pm 2 \%$ of forskolin-stimulated levels, respectively, which are lower than those observed for WT (Figure 5A and Table 1). Among single cysteine mutants, only C754A/C765A displayed WT-like response to L-AP4 (52 $\pm 5 \%)$ with an $\mathrm{EC}_{50}$ of 0.18 $\pm 0.04 \mu \mathrm{M}$ (Supplementary Table 2). Interestingly, there was no difference in the cAMP levels in the induced and uninduced cells of double cysteine mutant C793A. Remarkably, similar to C793A, the remaining two single cysteine mutants and the cys-less mutant which include C793A mutation demonstrated no change in cAMP levels on addition of L-AP4. Analogous to L-AP4, L-glutamate addition resulted in WT-like decrease in cAMP levels only in C754A/C765A but not in C793A containing mutants (Supplementary Table 2).

In contrast to L-AP4 responses, cAMP levels in WT and all the cysteine mutants were enhanced (185\% - 325\%; Figure 6A and Table 1) in presence of LY341495. This increase in cAMP levels was not present in corresponding uninduced controls. As expected, LY341495 induced elevation in cAMP levels were completely counteracted by L-AP4 (Figure 6B and Table 1). In presence of both LY341495 and L-AP4 (10 fold molar excess over LY341495), the cAMP levels in the mutants reflected those observed in L-AP4 alone controls (Figure 5A and 6B) suggesting competition binding between these ligands. Furthermore, these findings together with the receptor expression data from dot blot (Figure 3C) provide strong evidence that all the cysteine mutants are properly folded and trafficked to the membrane.

\section{GTP-Eu binding assay complements findings from cAMP assay for wild-type and cysteine mutants}

Unlike cAMP assay, which measures second messengers in cells, GTP-Eu binding is a direct membrane based assay to assess mGluR6 function [32]. GTP-Eu binding for WTmGluR6 in presence of L-glutamate was dose-dependent (saturated at $198 \pm 1 \%$ over basal 
A.

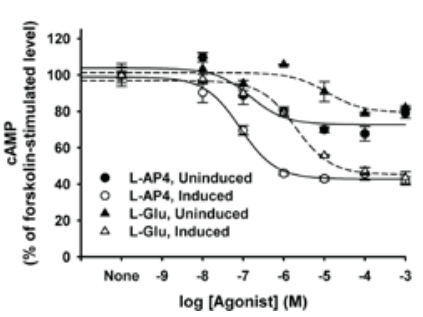

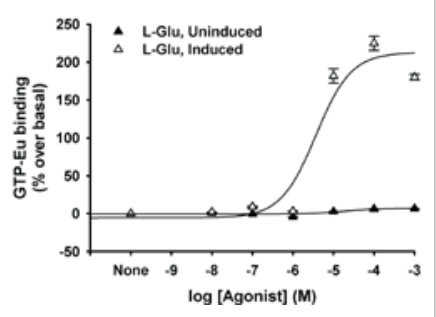

Figure 4: Dose response curves for wild-type mGluR6 in induced and uninduced stable cells/membranesfor (A) L-AP4 and L-glutamate in cAMP assay and for (B) L-glutamatein GTP-Eu binding assay.
A.

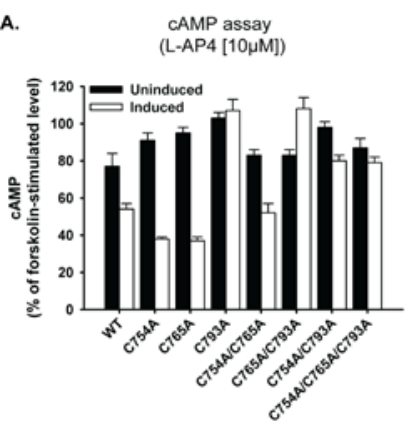

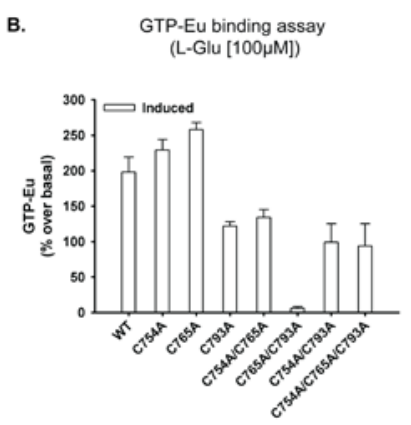

Figure 5: Response of wild-type and cysteine mutants to (A) L-AP4 in cAMP assay and (B) L-glutamate in GTP-Eu binding assay.Data for uninduced membranesin GTP-Eu binding assay is omitted as the percent over basal counts were very low $(<6 \%$; see figure $4 \mathrm{~B})$.

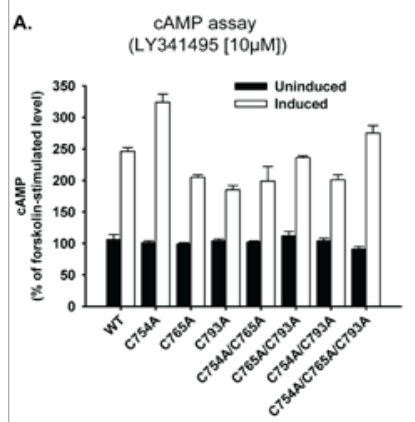

B. CAMP assay

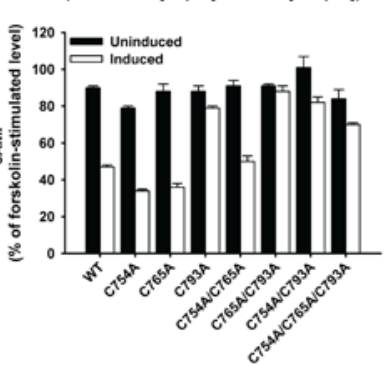

Figure 6: cAMP levels in induced and uninduced cells of wild-type and cysteine mutants to (A) LY341495 and (B) both LY341495 and L-AP4.

binding) with an $\mathrm{EC}_{50}$ value of $5 \pm 1 \mu \mathrm{M}$, which is similar to that observed in cAMP assays (Figure 4B; Table 1; Supplementary Table $2)$. There was very minimal binding $(<2 \%$; Figure $4 \mathrm{~B})$ in uninduced controls. Among double cysteine mutants, C754A and C765A had WT-like $\mathrm{EC}_{50}$ values (Supplementary Table 2) and enhanced GTP-Eu binding of $229 \pm 15 \%$ and $258 \pm 10 \%$, respectively, complementing the observations from cAMP assay. However, all other mutants containing C793A mutation, which were unresponsive to agonists in cAMP assay also displayed GTP-Eu binding but at much lower levels compared to WT. Surprisingly, the single cysteine mutant C754A/C765A which had WT like activity in cAMP assay showed lower GTP-Eu binding $(134 \pm 11 \%)$ compared to WT. Interestingly, only C765A/C793A had uninduced control-like binding levels of $6 \pm 2 \%$, lowest among all the mutants. The relative activities $\left(\mathrm{E}_{\max }\right)$ of all cysteine mutants as compared to WT are shown in Table 2. Unfortunately, L-AP4 directly interfered with GTP-Eu fluorescence (data not shown) and hence the binding assays could not be performed for L-AP4.

\section{Discussion}

The activation mechanism is very well studied in rhodopsin, the prototypical GPCR. In rhodopsin, residues on TM helices V and VI are most involved in ligand (11-cis retinal) binding and activation [33]. Analogous to 11-cis retinal binding pocket in rhodopsin, several residues on TM V and TM VI (Figure 2C) form the allosteric ligand binding pocket in mGluRs in general [15,34-36], but there have been no reported structure-function studies of mGluR6 to date. To evaluate the roles of these helices in mGluR6 activation, we mutated conserved cysteines.

To characterize the function of the mutant receptors, we optimized a cell based cAMP functional assay and developed a new membrane based GTP-Eu binding assay for mGluR6. In the cAMP assay, the highest activity in the presence of L-AP4 was observed for double cysteine mutants C754A and C765A (37\% -38\%), followed by WT and single cysteine mutant C754A/C765A (52\% - 54\%), All other cysteine mutants carrying the C793A mutation were inactive. GTP-Eu binding in general complemented the results observed with the cAMP assays. C754A and C765Ashowed elevated levels of GTP-Eu binding which positively correlates with the maximal inhibition of cAMP levels in cells. All the mutants with C793A show reduced levels of GTP-Eu binding in line with observed lack of activity in cAMP assays. The strongest reduction was observed for C765A/C793A, which had binding levels similar to uninduced controls. However, C754A/C765A which displayed WT-like activity in cAMP assays showed a negative correlation to GTP-Eu binding. The lack of correlation between indirect cell based cAMP and direct GTP binding functional assays has been reported before for GPCRs and cellular processes such as internalization, degradation, and desensitization are thought to play a role in the observed discrepancy [37]. Nevertheless, both cAMP and GTP-Eu binding data strongly suggest that C793 is critical for activation.

Interestingly, we observed enhanced levels of cAMP on addition of LY341495 in both WT and all the cysteine mutants. This increase in cAMP levels was seen in the presence forskolin and in the induced cells only, suggesting that LY341495 does not directly modulate adenylyl cyclase but acts through mGluR6. Similar increase in cAMP levels in the presence of a LY341495 has previously been reported for mGluR4, mGluR7 and mGluR8 [29]. One possible explanation for this observation is that LY341495 is competing out the effect of endogenous L-glutamate in the assay. However, this explanation does not account for the observed elevation in cAMP levels even for cysteine mutants which showed no response to L-glutamate. Moreover, in our assay system we expect negligible levels of endogenous L-glutamate since we nutrient starve the cells in HBSS in preparation for the functional assay. We hypothesize that LY341495 is acting as an inverse agonist in our system by shifting the equilibrium of spontaneously active mGluR6 to $G$ protein bound inactive complex, a phenomenon which is usually observed in highly over expressing systems [38].

Our study provides evidence that $\mathrm{C} 793^{6.45} \mathrm{~A}$ mutation (Note: The generic numbering proposed by Ballesteros and Weinstein [21] is included as a superscript for following part of discussion.) compromises agonist response in mGluR6, while $\mathrm{C} 754^{5.46} \mathrm{~A}$ and $\mathrm{C} 765^{5.57} \mathrm{~A}$ slightly enhance the activation. A comparative sequence alignment of TM $\mathrm{V}$ and TM VI regions of mGluR6, rhodopsin, mGluR1 and mGluR5 is shown in Figure 2C. Residues C754 $4^{5.46}$ and $\mathrm{C} 793^{6.45}$ are adjacent to critical residues that are part of the ligand binding pocket in the TM 
(Figure 2C). In rhodopsin, TM V forms hydrogen bond interactions with TM III [12] and it is possible that the C754.46 A and $\mathrm{C} 765^{5.57} \mathrm{~A}$ mutations in mGluR6 stabilize TM III-TM V interactions in the activated state. Interaction between TM III and TM V for maintaining the function of the receptor, have been previously shown for mGluR8 [39].

On the other hand, TM VI does not pack closely with any helices except at the ionic lock $[12,40]$ and is the major moving helix in activation of rhodopsin and other GPCRs [41-43]. C793 ${ }^{6.45}$ is part of the TM VI stretch that has important residues that are conserved across all GPCRs such as W265 $5^{6.48}$ in rhodopsin. In mGluR6, the C793 ${ }^{6.45} \mathrm{~A}$ mutation is located in the middle of TM VI and thus, probably compromises its movements necessary for activation. This suggests that the rotamer toggle switch of $\mathrm{W} 265^{6.48}$ in rhodopsin $\left(\mathrm{W}^{6.48}\right.$ is also conserved in mGluRs) known to be a key element in the activation for many GPCRs may prevail in mGluR6. Helix VI is the most conserved helix in mGluRs and our findings strongly support the generality hypothesis that this helix plays a major role in activation of Class $\mathrm{A}$ and Class C GPCRs alike.

\section{Acknowledgements}

This work is supported by National Institutes of Health Grant R01 LM00799408. We thank Dr. Phyllis Robinson (University of Maryland, Baltimore, MD) for providing mGluR6plasmid DNA.

\section{References}

1. Conn PJ, Pin JP (1997) Pharmacology and functions of metabotropic glutamate receptors. Annu Rev Pharmacol Toxicol 37: 205-237.

2. Pin JP, Duvoisin R (1995) The metabotropic glutamate receptors: structure and functions. Neuropharmacology 34: 1-26.

3. Nakajima Y, Iwakabe H, Akazawa C, Nawa H, Shigemoto R, et al. (1993) Molecular characterization of a novel retinal metabotropic glutamate receptor mGluR6 with a high agonist selectivity for L-2-amino-4-phosphonobutyrate. J Biol Chem 268: 11868-11873.

4. Dryja TP, McGee TL, Berson EL, Fishman GA, Sandberg MA, et al. (2005) Night blindness and abnormal cone electroretinogram ON responses in patients with mutations in the GRM6 gene encoding mGluR6. Proc Natl Acad Sci U S A 102: 4884-4889.

5. O'Connor E, Allen LE, Bradshaw K, Boylan J, Moore AT, et al. (2006) Congenital stationary night blindness associated with mutations in GRM6 encoding glutamate receptor MGluR6. Br J Ophthalmol 90: 653-654

6. Zeitz C, van Genderen M, Neidhardt J, Luhmann UF, Hoeben F, et al. (2005) Mutations in GRM6 cause autosomal recessive congenital stationary night blindness with a distinctive scotopic $15-\mathrm{Hz}$ flicker electroretinogram. Invest Ophthalmol Vis Sci 46: 4328-4335.

7. Nielsen DA, Ji F, Yuferov V, Ho A, Chen A, et al. (2008) Genotype patterns that contribute to increased risk for or protection from developing heroin addiction. Mol Psychiatry 13: 417-428.

8. Fonseca F, Gratacos M, Escaramis G, De Cid R, Martin-Santos R, et al (2010) Response to methadone maintenance treatment is associated with the MYOCD and GRM6 genes. Mol Diagn Ther 14: 171-178.

9. Klein-Seetharaman $J(2002)$ Dynamics in rhodopsin. Chembiochem 3: $981-$ 986.

10. Hubbell WL, Altenbach C, Hubbell CM, Khorana HG (2003) Rhodopsin structure, dynamics, and activation: a perspective from crystallography, sitedirected spin labeling, sulfhydryl reactivity, and disulfide cross-linking. Adv Protein Chem 63: 243-290.

11. Altenbach C, Kusnetzow AK, Ernst OP, Hofmann KP, Hubbell WL (2008) Highresolution distance mapping in rhodopsin reveals the pattern of helix movement due to activation. Proc Natl Acad Sci U S A 105: 7439-7444.

12. Ahuja S, Smith SO (2009) Multiple switches in G protein-coupled receptor activation. Trends Pharmacol Sci 30: 494-502.

13. Noeske T, Gutcaits A, Parsons CG, Weil T (2006) Allosteric Modulation of Family 3 GPCRs. QSAR \& Combinatorial Science 25: 134-146.
14. Goudet C, Gaven F, Kniazeff J, Vol C, Liu J, et al. (2004) Heptahelical domain of metabotropic glutamate receptor 5 behaves like rhodopsin-like receptors. Proc Natl Acad Sci U S A 101: 378-383.

15. Yanamala N, Tirupula KC, Klein-Seetharaman J (2008) Preferential binding of allosteric modulators to active and inactive conformational states of metabotropic glutamate receptors. BMC Bioinformatics 9 Suppl 1:S16.

16. Rondard P, Goudet C, Kniazeff J, Pin JP, Prezeau L (2011) The complexity of their activation mechanism opens new possibilities for the modulation of $\mathrm{mGlu}$ and GABAB class C G protein-coupled receptors. Neuropharmacology 60: 82 92.

17. Gether U (2000) Uncovering molecular mechanisms involved in activation of $G$ protein-coupled receptors. Endocr Rev 21: 90-113.

18. Schwartz TW, Frimurer TM, Holst B, Rosenkilde MM, Elling CE (2006) Molecular mechanism of 7TM receptor activation--a global toggle switch model. Annu Rev Pharmacol Toxicol 46: 481-519.

19. Eswar N, Webb B, Marti-Renom MA, Madhusudhan MS, Eramian D, et al (2007) Comparative protein structure modeling using MODELLER. Curr Protoc Protein Sci Chapter 2: Unit 29.

20. Laskowski RA, MacArthur MW, Moss DS, Thornton JM (1993) PROCHECK: a program to check the stereochemical quality of protein structures. J Appl Crys 26: 283-291.

21. Ballesteros JA, Weinstein $H$ (1995) [19] Integrated methods for the construction of three-dimensional models and computational probing of structure-function relations in G protein-coupled receptors. Methods in Neurosciences 25: $366-$ 428

22. Reeves PJ, Kim JM, Khorana HG (2002) Structure and function in rhodopsin a tetracycline-inducible system in stable mammalian cell lines for high-level expression of opsin mutants. Proc Natl Acad Sci U S A 99: 13413-13418.

23. Weng K, Lu C, Daggett LP, Kuhn R, Flor PJ, et al. (1997) Functional coupling of a human retinal metabotropic glutamate receptor (hmGluR6) to bovine rod transducin and rat $\mathrm{Go}$ in an in vitro reconstitution system. J Biol Chem 272: 33100-33104.

24. Song GJ, Barrick S, Leslie KL, Sicari B, Fiaschi-Taesch NM, et al. (2010) EBP50 inhibits the anti-mitogenic action of the parathyroid hormone type 1 receptor in vascular smooth muscle cells. J Mol Cell Cardiol 49: 1012-1021.

25. Salomon Y, Londos C, Rodbell M (1974) A highly sensitive adenylate cyclase assay. Anal Biochem 58: 541-548.

26. Yamashita T, Terakita A, Kai T, Shichida Y (2008) Conformational change of the transmembrane helices II and IV of metabotropic glutamate receptor involved in G protein activation. J Neurochem 106: 850-859.

27. Pin JP, Galvez T, Prezeau L (2003) Evolution, structure, and activation mechanism of family $3 / \mathrm{C}$ G-protein-coupled receptors. Pharmacol Ther 98 325-354.

28. Laurie DJ, Schoeffter P, Wiederhold KH, Sommer B (1997) Cloning, distribution and functional expression of the human mGlu6 metabotropic glutamate receptor. Neuropharmacology 36:145-152.

29. Kingston AE, Ornstein PL, Wright RA, Johnson BG, Mayne NG, et al (1998) LY341495 is a nanomolar potent and selective antagonist of group II metabotropic glutamate receptors. Neuropharmacology 37:1-12.

30. Wright RA, Arnold MB, Wheeler WJ, Ornstein PL, Schoepp DD (2000) Binding of $[3 \mathrm{H}](2 \mathrm{~S}, 1$ 'S,2'S)-2-(9-xanthylmethyl)-2-(2'-carboxycyclopropyl) glycine ([3H]LY341495) to cell membranes expressing recombinant human group III metabotropic glutamate receptor subtypes. Naunyn Schmiedebergs Arch Pharmacol 362: 546-554.

31. Arunlakshana O, Schild $\mathrm{HO}$ (1959) Some quantitative uses of drug antagonists Br J Pharmacol Chemother 14: 48-58.

32. Frang H, Mukkala VM, Syysto R, Ollikka P, Hurskainen $P$, et al. (2003) Nonradioactive GTP binding assay to monitor activation of $\mathrm{g}$ protein-coupled receptors. Assay Drug Dev Technol 1: 275-280.

33. Palczewski K, Kumasaka T, Hori T, Behnke CA, Motoshima $\mathrm{H}$, et al. (2000) Crystal structure of rhodopsin: A G protein-coupled receptor. Science 289: 739745.

34. Fukuda J, Suzuki G, Kimura T, Nagatomi Y, Ito S, et al. (2009) Identification of a novel transmembrane domain involved in the negative modulation of mGluR1 using a newly discovered allosteric mGluR1 antagonist,3-cyclohexyl-5-fluoro6-methyl-7-(2-morpholin-4-ylethoxy)-4H-chromen-4-one. Neuropharmacology 57: 438-445. 
Citation: Tirupula KC, Dhiman HK, Murthy L, Bisello A, Klein-Seetharaman J (2012) Role of Conserved Transmembrane Domain Cysteines in Activation of Metabotropic Glutamate Receptor Subtype 6. Med chem 2: 119-125. doi:10.4172/2161-0444.1000126

35. Malherbe P, Kratochwil N, Muhlemann A, Zenner MT, Fischer C, et al. (2006) Comparison of the binding pockets of two chemically unrelated allosteric antagonists of the mGlu5 receptor and identification of crucial residues involved in the inverse agonism of MPEP. J Neurochem 98: 601-615.

36. Muhlemann A, Ward NA, Kratochwil N, Diener C, Fischer C, et al. (2006) Determination of key amino acids implicated in the actions of allosteric modulation by 3,3 '-difluorobenzaldazine on rat mGlu5 receptors. Eur $\mathrm{J}$ Pharmacol 529: 95-104.

37. Kim JM, Hwa J, Garriga P, Reeves PJ, RajBhandary UL, et al. (2005) Lightdriven activation of beta 2 -adrenergic receptor signaling by a chimeric rhodopsin containing the beta 2-adrenergic receptor cytoplasmic loops. Biochemistry 44 : 2284-2292.

38. Kenakin T (2004) Principles: receptor theory in pharmacology. Trends Pharmacol Sci 25:186-192.
39. Yanagawa M, Yamashita T, Shichida $Y$ (2009) Activation switch in the transmembrane domain of metabotropic glutamate receptor. Mol Pharmacol 76: 201-207.

40. Patel AB, Crocker E, Reeves PJ, Getmanova EV, Eilers M, et al. (2005) Changes in interhelical hydrogen bonding upon rhodopsin activation. J Mol Biol 347: 803-812.

41. Farrens DL, Altenbach C, Yang K, Hubbell WL, Khorana HG (1996) Requirement of rigid-body motion of transmembrane helices for light activation of rhodopsin. Science 274:768-770.

42. Park JH, Scheerer P, Hofmann KP, Choe HW, Ernst OP (2008) Crystal structure of the ligand-free G-protein-coupled receptor opsin. Nature 454:183-187.

43. Scheerer P, Park JH, Hildebrand PW, Kim YJ, Krauss N, et al. (2008) Crystal structure of opsin in its G-protein-interacting conformation. Nature 455: 497502. . 